\title{
Play in professional education: vets who horse around
}

\author{
Jill Rowan Deans MacKaya*
}

Email: jill.mackay@ed.ac.uk Twitter:@jilly_mackay

\section{Katie Stein ${ }^{\mathrm{a}}$}

\section{Sarah Chinnery ${ }^{\mathrm{a}, \mathrm{b}}$}

\section{Steph Smith}

\section{Jessie Paterson ${ }^{\mathrm{a}}$}

a Royal (Dick) School of Veterinary Studies, the University of Edinburgh, Scotland, EH25 9RG

b PDSA, Glasgow

\section{A RTICLE INFO}

Article history:

Received 29 October '19

Accepted 30 March '21

\section{Keywords:}

Playful learning

Pedagogical design

Professional practice

Roleplay

Educational evaluation

\begin{abstract}
A BSTRACT
Play in professional learning can be a disputed topic, with paradoxical frameworks such as 'serious play' being used to legitimise playful practice in these settings. Despite this, play can be a valuable tool in learning, particularly in encouraging adults to deal with uncomfortable situations such as personal failures. In partnership with students, we developed a playful roleplay scenario for first year veterinary students in a UK veterinary school. 102 students engaged in the roleplay scenario and $82 \%$ (84) engaged with a student-led evaluation with a pre and post session survey. A focus group with staff was also run to explore the value of running a playful session in an accreditation driven curriculum such as the veterinary programme. $91.7 \%$ of participants rated the scenario as enjoyable and $84.5 \%$ felt it should be used within the veterinary curriculum, but reflections from staff revealed complex interactions between students' individual differences and the value of the session. Ultimately, the playful session was considered valuable for these learners, however there is a range of considerations for adopting play in professional practices.
\end{abstract}

\section{Introduction}

'Play' in learning is a complex topic with multifactorial challenges, not least the difficulty of defining play in humans (Gordon, 2009). For adults, another challenge can be legitimising play as a practice, which has prompted the development of so-called 'paradoxical' frameworks such as serious play (Statler, Heracleous, \& Jacobs, 2011). Play can have great value in professional settings, supporting creativity and innovation (West,

Published under Creative Commons License 4.0

First publications rights: (C) University of Huddersfield Press unipress.hud.ac.uk 
Hoff, \& Carlsson, 2016) and is well recognized as a valuable tool in education (Whitton \& Maclure, 2015). In this study we discuss the challenges inherent in introducing playful learning interventions in a professional degree programme (the veterinary curriculum) and consider how play can be incorporated in these settings.

\section{Play in Adult Learning}

While play is often recognised as important, it can be challenging to identify what 'counts' as play. Gordon (2009, p. 12) proposes a broad definition of play in humans where: "Play is the voluntary movement across boundaries, ... releasing tension in ways that are pleasurable, exposing players to the unexpected, and making transformation possible". Play is nearly universally recognised as important for early-years education, but it has been in decline as accountability drives more performance-indicator friendly activities in early-year education (Bergen, 2002). Play within higher education often focuses around role-play scenarios, used very effectively in clinical education as a form of active learning (Acharya, Shukla, Acharya, \& Vagha, 2014; DeNeve \& Heppner, 1997). Good role-play scenarios require time for feedback and reflection, set learning outcomes and challenging cases (Joyner \& Young, 2006) in order to be most effective. Joyner \& Young also highlight that role-play gives students an opportunity to have 'fun', and yet most clinical role-play scenarios are reflective of real-world situations. It has been suggested that great suspension of disbelief can be created through online role-play (Morse, Littleton, Macleod, \& Ewins, 2009), allowing for more exploration of considerations in gender and race than traditional face-to-face roleplay due to freedom from physical constraints. For adults, 'playfulness' is often assumed to have a detrimental effect on productivity, and yet is seen in a wide variety of job roles and across a broad demographic (Starbuck \& Webster, 1991). The narrative aspect of play, sometimes referred to as 'mimesis', allows for interpretive representation of real-world aspects through creative outlets (Feldman, 2005). Which is to say, one of the neglected aspects of play for adults, is that it does not have to explicitly represent the ideas of interest in order to be valuable.

For higher education, it is important also to differentiate 'playfulness' from 'gamification'. Gamification is the exploitation of game-techniques in order to increase a student's motivation to perform a learning task (Deterding et al., 2011). Playfulness instead uses creativity and fun to encourage active learning (Whitton \& Maclure, 2015). Playfulness also aims to encourage low-consequence failures (Whitton, 2015). The theory being that playful spaces encourage the viewing of failure as a learning opportunity, and not a penalty. Failure within games has an ability, possibly unique, to be divorced from personal failure (Gee, 2003), and yet as Feldman (2005) could consider, the narrative of failure can still help a person consider and reflect upon their own response to failure. As failure, and the student's response to failure, can be an important element of resilience and wellbeing (Whittington, Rhind, Loads, \& Handel, 2017; Yeager \& Dweck, 2012), playfulness may open up engaging avenues of improving resilience within students. 
These theories have led to an interest within educational literature in a 'Kobayashi Maru' scenario. This hallmark of Star Trek canon features a test which is unwinnable, teaching all Star Trek captains the value of failure and how to move on from it (Stemwedel, 2015). Higher education institutions have begun to explore 'nowin' scenarios as a mechanism for teaching students resilience skills (Bruni-Bossio \& Willness, 2016). Other interpretations of the no-win scenario, such as within the US military, have been used to teach the value of 'alternative' strategies, or the value of 'cheating' (Conti \& Caroland, 2011).

\section{The Veterinary Context}

In the UK, the veterinary medicine and surgery undergraduate degree is taught to the Royal College of Veterinary Surgeons (RCVS) professional standards (RCVS, 2019). The UK's veterinary schools must produce students who can meet the RCVS 'day one competencies', minimum standards of practical skills, knowledge and attitudes which graduates must be able to demonstrate. The curriculum can be referred to as 'accreditation driven', as individual schools lack the same controls over content that a non-professional degree might have. A typical veterinary degree lasts for five years and has a pre-clinical period for the first two years where students attend theory-heavy lectures, a clinical phase for the third and fourth years where students learn practical skills, and a professional fifth year where students work in practice. Throughout the degree, students also work on extra-mural studies or EMS placements where they are hosted by an industry partner. Shorter graduate entry degrees typically condense the pre-clinical teaching to one year, but still feature the EMS placements and have the same graduate requirements. The veterinary undergraduate population has a higher prevalence of mental health challenges than the typical undergraduate population, in line with the mental health estimates of the veterinary profession (Cardwell et al., 2013). Students report feeling under-prepared (Langebæk, Eika, Tanggaard, Lundorff, \& Berendt, 2012).

One of the important definitions of a day 1 competent vet is that a new graduate is expected to be 'capable and confident enough to practise veterinary medicine at a primary care level on their own, while knowing when it is appropriate to seek direction from more experienced colleagues' (RCVS, 2014, emphasis ours). Students should have an accurate awareness of their abilities and limitations, which cannot be constructed without experiencing being unable to meet certain criteria. The assessment literacy concept suggests that students should also be able to identify why they did not meet the criteria, and how they can meet it in future (Rhind \& Paterson, 2015). In this way, formative assessments can be considered low-consequence failure opportunities, where students can explore the boundaries of their ability while not sacrificing their overall goal, e.g. a continued high Grade Point Average (GPA). This is particularly important for professional degrees such as the veterinary profession, where a practitioner being unable to correctly identify their own limitations can have extreme consequences for individual and public health. Resilience in the veterinary profession is oft-discussed 
in light of the veterinary student population which is highly driven and motivated (Rhind \& Grant, 2017; Whittington et al., 2017). Our initial premise was that a playful learning scenario would support veterinary students to appreciate failure as a learning opportunity, while protecting their own innate resilience properties.

\section{Materials and Methods}

\section{Ethics}

Ethical permission for the evaluation of this intervention was obtained from the Human Ethical Review Committee at the Royal (Dick) School of Veterinary Studies, reference: HERC_204.

\section{Development}

Development of the playful intervention was focused around the aim of encouraging students to experience failure. A role-play scenario was deemed suitable due to the long history of role-play in higher education, particularly in medical education (DeNeve \& Heppner, 1997; Joyner \& Young, 2006; Morse et al., 2009). There were five lecturers involved in the creation of the scenario, two veterinary professionals, two professionals adjunct to the veterinary industry (JM \& JP) and one lecturer from the School of Education. There were several key aims for the educational scenario: 1) the scenario should encourage playful behaviour, e.g. the voluntary crossing of boundaries; 2) the scenario should allow students to explore unethical behaviour, which is ordinarily of high consequence to veterinary professionals; 3 ) the scenario should introduce students to failure within the scaffolded setting of the $1^{\text {st }}$ year Professional Skills course.

Original considerations included 'escape rooms', with series of tasks which employed skill and knowledge based puzzles which sequentially must be tackled in order to win, per Eukel, Frenzel and Cernusca, (2017). However this was deemed impractical for a first year cohort of students with limited practical and theoretical knowledge. Through personal experience, a role-play scenario was selected drawing gameplay elements from 'murder mystery' games. A zombie apocalypse scenario was written by JM for 20-30 players. Aspects of public health were incorporated into the game, including infection control procedures, to make it relevant to the veterinary setting, but there were also ethical dilemmas, such as immigration and conflicts of evidence in journalism. During the scenario, each student would receive a character role such as 'Mayor' or 'Doctor'. These roles would come with some information regarding the scenario and a personal goal. All students would also receive generic information and instructions.

When students enter the scenario they are informed of the game's intent to 'defeat them [the players]' and that they each have an individual goal. They are also informed that their overall goal, and the most important goal, is to keep the town of Roslin alive during exposure to the zombieitis disease. The students are not told that most personal goals directly contravene keeping the town of Roslin alive (e.g. facilitate disease spread, destabilise the 
community). They are informed that they should be careful who they reveal their personal goal to, as other players may have a similar or opposing goal. Students are told that information is critical within the game, and information cannot be freely shared among tables due to quarantine restrictions. This is enforced by student helpers (see below).

The scenario has three broad story events: a political coup; a reveal of 'poor science' which undermines the town's understanding of the zombie disease; and a trial which may see one of the town's own convicted of endangering Roslin (through no fault of that specific player). These three events are used to encourage players to behave unethically, e.g. a character may be in possession of important information regarding the Mayor which can be used as leverage by those in the political coup storyline.

An important gameplay aspect is 'information flooding'. Each player receives their character sheet and additional 'generic' information about the scenario context, e.g. a fictional history of the town of Roslin. There are also leaflets from pharmaceutical companies and Zombie Rights Activists. Players must critically evaluate this evidence with limited additional information to establish what is important. It was expected that this would increase the stressful aspects of the game, and contribute to personal sense of failure when the town of Roslin falls.

Throughout all aspects of the scenario development, an important element of this project was the use of students as partners in academic design (see Bovill, Cook-Sather, \& Felten, 2011; Bovill \& Woolmer, 2018). A group of $4^{\text {th }}$ year (penultimate year) students undertaking the Undergraduate Certificate in Veterinary Medical Education (UCVME, see Hudson et al., 2016) were recruited via email. These students tested an original version of the scenario for 20 players, and provided valuable feedback for the scaled up version which runs for 30 players.

The class size for this year group was 102, with students typically being separated into 4 smaller A-D groups for smaller group teaching. Therefore the scenario needed to work with between 20 and 30 characters, depending on group size. Within each group there were 2 to 3 UCVME student helpers who were on hand to answer student questions, and to 'stir up trouble' when they considered students to be behaving too ethically. The student helpers therefore would encourage rule-breaking as they saw fit, with the overall goal of encouraging behaviour that would lead to the ultimate spread of the zombie disease throughout the town.

At the end of the 90 minute scenario, all students were recalled for a debrief and a discussion of the importance of failure within the veterinary profession. This included a debrief of the scenario's events from JM, and then pre-recorded videos of staff members discussing personal and professional failures in practice. The debrief was focussed around explaining the learning outcomes of the session, that we had intended the students to fail, and why we considered this learning was important for the veterinary programme. The debrief highlighted that 
unethical behaviour can be the result of conflicting pressures, and encouraged empathy and critical reasoning skills in such cases.

\section{Evaluation}

The evaluation of the student perspective was led by KS, one of the project's student partners. Two paper surveys were administered to student participants before and after the session was run $(n=84,82 \%$ response rate). In the pre-survey, students rated their communication skills, teamwork, ethical decision making, and ability to cope with failure on a 5-point Likert-like scale. In the post-survey, students were asked to rate how well they felt the scenario helped them improve their communication skills, teamwork, ethical decision making and ability to cope with failure on a 5-point Likert-like scale. Students were also asked a series of 'yes/no' questions regarding the operation of the scenario, whether it was clear, ran for an appropriate length of time, was stressful, enjoyable, and whether it should be used in the veterinary course. Students were also given the opportunity to comment on the scenario in the post-survey. Due to on-the-day timings, the post survey was administered prior immediately after the scenario concluded and prior to the whole-class debrief. A retention survey was delivered in the second semester via email, with only 9 respondents (10.7\% response rate) which asked the same questions from the pre-survey again. KS thematically coded the comment data. Likert-like data was analysed using the Likert package (Bryer \& Speerschneider, 2016) in R (R Core Team, 2019) by JM.

Comparisons between pre and retention survey results were drawn via Kruskal Wallis tests.

Additionally, SC ran a focus group with the staff members involved in designing the activity (including authors JM \& JP), and a transcript of this was thematically coded by SS to explore the value of running a playful session such this one. JM collated the analyses done by KS and SS respectively.

\section{Results}

\section{Scenario observations}

Four incidences of scenario were run and each scenario explored different narrative 'outcomes', with students pursuing different agendas. All four groups 'failed' in their ability to contain the zombie disease, with different 'mistakes' being made. The branching narrative subplots played out in different ways. For example, in one playthrough, a 'concerned citizen' character used the political coup subplot to become the elected Mayor, leading to an open election held in that version of the 'town' which was not seen in the other regions. The player's motivation was to obtain a rare vaccine, which they were able to use their newfound Mayoral powers to do. This character role did not pursue this path in the other three groups (although in one group, the character had obtained a vaccine through another method). Players used the letter-based communication system conservatively, with only some players thinking to use items like pharmaceutical leaflets to write on and 
send additional information to other players. Some students invented their own narratives, such as a crowd funding resource to develop more effective vaccines.

There were varied examples of roleplay in the scenarios. One communication between players read:

Dear Doctor, I am a supplies officer, who has a crucial role as resources are limited and I am the one who contacts travellers and traders to ensure that sufficient food and vaccines for the people trapped here [sic]. Thus, its important that I do not get infected by the disease. Please allow me to get a vaccination as I play a critical role and I must be protected from the bacteria or everyone will starve and die. Thanks. Supplies Officer.

A series of far briefer exchanges were noted on one of the game's official forms. This represented innovative use of materials (multiple persons communicating on an otherwise restricted use form) and unethical behaviour (the player with the 'puppies' is exaggerating, they only have the potential to breed new puppies):

[after requesting to move districts]

Player 1: Why do you want to move :-)?

Player 2: I need a vaccine, I have puppies (-)

Player 3: There are no vaccines

There was also evidence of students using exam skills to process the information they had received (Figure 1). 
Figure 1: Example of information processing from a student, note highlighted sections of text.

\section{Briefing: Traveller 2}

Overview:

You need to find shelter and you need to find it fast. It's dangerous out there, and there's a lot you
could contribute to a community. Information You know:

The world out there is a scary place, and about three hours ago you sneaked past a pretty large horde of zombies. If they heard you, they're probably right on your tail.

It might not be wise to tell the guards that.

Traveller 1 keeps going on about a dog they saw - you didn't see this dog.

You've been keeping a diary of all the zombie movements you've seen lately. That information would be pretty useful to any researchers. You're not daft though - you've written it in a secret
code.

Your Health:

You're tired, and you're sore, but you're okay.

You are not vaccinated,

\section{Student perspective}

Prior to the survey, students generally rated their skills with regard to teamwork ( $74 \%$ positive), ethical decision making (65\% positive), and communication ( $55 \%$ positive) positively. However only $32 \%$ of students rated their ability to cope with failure positively. There were no significant differences between students' rating of their skills prior to the survey and in the 6 month retention survey in Kruskal Wallis tests (Figure 2). Students were less positive about how the scenario helped them develop their skills with $51 \%$ of students negatively rating the scenario's ability to help them cope with failure and $43 \%$ of students negatively rating the scenario's ability to help them with ethical decision making (Figure 3.) 
Figure 2: Students' self-ratings on skills immediately prior and 6 months post the zombie role-play intervention $(\mathrm{n}=83)$.

Please rate your own skills ( 1 being poor, 5 being excellent)

(Pre Survey, $n=83$, Retention Survey, $n=9$ )

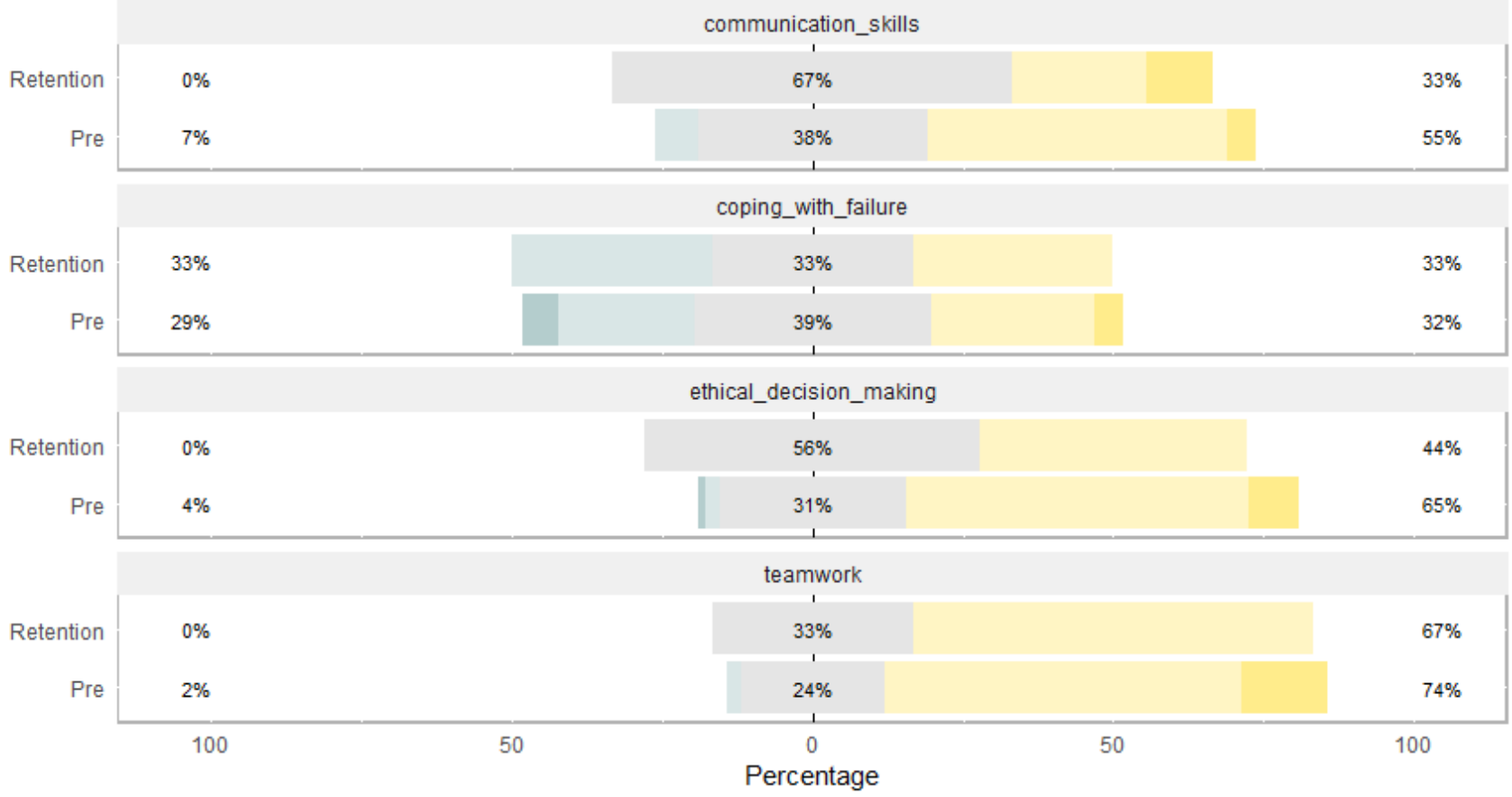

\begin{tabular}{l|l|l|l|l|l|l|} 
Response & 1 & 2 & 3 & 4 & 5 \\
\hline
\end{tabular} 
Figure 3: Students' self-ratings of how the scenario helped them develop these skills after the zombie role-play intervention $(n=83)$.

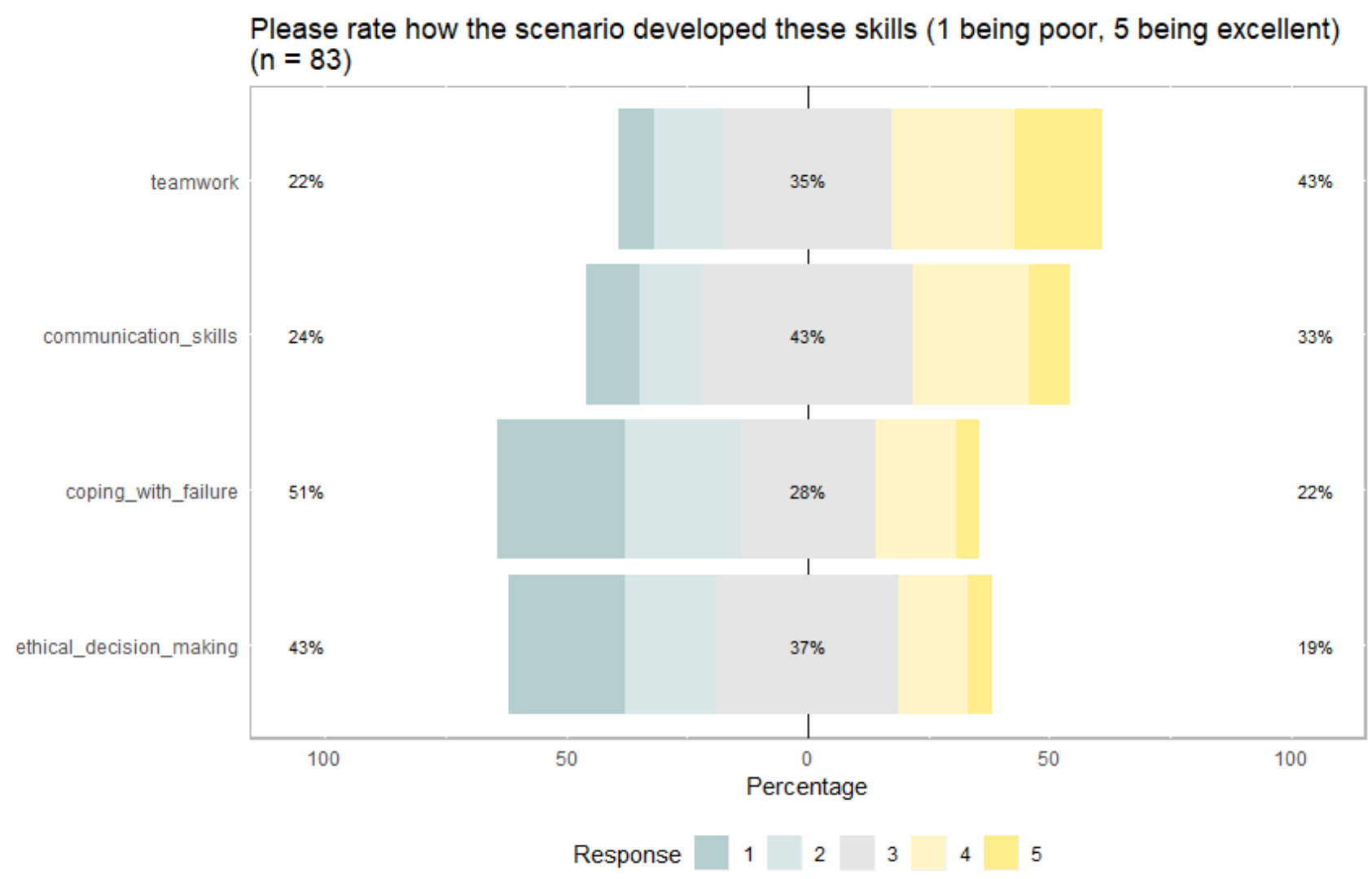

Only 25\% ( $n=21)$ students considered the scenario stressful. The majority of students felt the aims and objectives of the scenario were clearly explained $(76.2 \%, n=64)$, that the scenario itself was clearly explained $(86.9 \%, n=73)$, and that their own role was clear $(82.1 \%, n=69)$. The scenario was also considered enjoyable $(91.7 \%, n=77)$ and to have lasted for an appropriate time $(77.4 \%, n=65) .84 .5 \%(n=71)$ of students felt the scenario should be used within the veterinary curriculum.

Within the free text comments from the post survey and retention survey, there was variety in perspectives. Of those who were critical of scenario, a common concern was related to clarity of instruction. A number of people stated that the objective and rules of the game were not clear, and that more time should have been given. Some of these players did acknowledge that the scenario became clearer as they progressed through the game. Some students also found the 'failure' difficult to identify, stating they hadn't felt the failure personally.

In the retention survey, students were asked to reflect on the scenario and its place in the professional degree. There were comments that: 
The zombie theme was a bit silly

[Play should be used] only if it is implemented effectively. I believe there should be a distinction between work and play and if by implementing play into our work environment it is not done effectively, it might disrupt our work environment, leading to adverse effects (working less, putting less effort, etc.)

I learned more from that one class we had than half my lectures if I hadn't studied.

\section{Staff perspective}

The consensus from the focus group was that the student response from this activity was varied; as students had commented to staff that the session was 'fun', 'stressful', but could have been perceived as 'time wasting'. It was agreed that the outcome very much depended on a student's personality and the role they were given. Some roles inevitably featured more power, and this was a source of concern. However staff did witness students in 'low power' roles end the game with a great deal of personal power, depending on how they had played. Staff commented that: 'not everyone is going to be in same place after this', highlighting the highly personal nature of this kind of learning experience.

One of the successes of the activity from the staff perspective was clearly the involvement of the fourth years or 'senior colleagues' to the students who were described as 'invaluable', and encouraged the first years with things that might not 'occur naturally'.

The staff concerns were mainly around making the scenario relevant to the students' professional development. The staff acknowledged that many of these lessons may not necessarily be apparent immediately following the activity, but may become more relevant later in their studies. The issue of rule clarity was also raised by staff, with a distinction drawn between intentional rule breaking being 'better facilitated' versus breaking the rules 'because [the students] forgot about them'.

\section{Discussion}

There were a number of challenges associated with incorporating a playful learning session into a professionalized degree programme. Many of these challenges relate to the practical aspects of running a branching interactive session for a large cohort of students, but others relate more specifically to the challenges of introducing play in professional contexts. The three aims of the playful scenario were: 1) to encourage playful behaviour, e.g. the voluntary crossing of boundaries; 2) to allow students to explore unethical behaviour; 3) to introduce students to failure within a scaffolded setting. Our evaluation covers all three aims, with recommendations for future practice.

\section{Did students play?}

As per Gordon's definition of play (2009), we observed voluntary boundary crossing, such as the roleplay and 
generation of new ideas, and this was pleasurable for at least some of the students who partook in the scenario. The structure of the game caused challenges for some students, with the rules only becoming clear with experience. Adult play often requires socially approved settings or 'permission' from social constructs (Walsh, 2019), and adults may 'disrupt' children's play through enforcing rules (Frost, 2004). Many students may have been unfamiliar with playful framings. In our own reflections on the study we have theorised that there may be an element of playful literacy, with some students having to 'catch up' with the social framing of play before they were able to engage with the scenario. This playful literacy concept has led to the development of a further study investigating how readily individuals have access to play. There is some evidence to suggest that those who have more playful backgrounds have greater resilience, even in late adulthood, and that this shows individual variation (Chang, Yarnal, \& Chick, 2016), and this natural variation in playfulness may be an inherent challenge within playful learning interventions.

\section{Did students explore ethical conflict?}

A result of particular note is students' perceptions of ethics within the scenario, with only $19 \%$ of students rating the scenario positively for teaching ethical decision making skills. There has been great discussion surrounding the teaching of veterinary ethics (Magalhaes-Sant'Ana, 2014; Main, Thornton, \& Kerr, 2005) as in practice, veterinarians will be introduced to many ethical dilemmas (Batchelor \& McKeegan, 2012).

Veterinarians may be asked by their clients to behave in a way that is considered unethical, and have a role in guiding clients with empathy and consideration (Mullan, 2012). Some aspects of veterinary education have been criticised for encouraging 'acquiescence' to authority (Batchelor, Creed, \& McKeegan, 2015), often due to hidden curriculums (Snyder, 1971). Our intent was to provide students an opportunity to explore how they made ethical decisions, and to subtly highlight the personal conflicts that can create challenges for ethical reasoning. The staff within the scenario were not concerned about teaching students to behave unethically much as in Conti \& Caroland (2011), as the debrief explicitly framed this as an opportunity for students to explore why unethical behaviour occurs. It should be noted that the debrief occurred after the post-survey was administered, and so the debrief may have reassured students again regarding their ethical decision-making abilities, or better contextualised how this learning fitted into the curriculum. The retention survey comments did show evidence of students considering how the scenario complemented the rest of their studies, with requests for 'effective' implementation. One of our recommendations is therefore the addition of a highly structured debrief setting (see below) which will be used to scaffold the learning.

\section{Did students fail?}

During development of the playful scenario it was decided to be open with students regarding the game's purpose, and to tell them explicitly that the game was trying to 'beat them'. Although some students found the 
experience stressful, it was also difficult for students to identify the failure in the scenario. In addition, there was no significant difference in students' ratings of the ability to deal with failure after the session had taken place. There are a number of possible explanations for these findings. It may be that the session did not generate feelings of failure at the time, and that throughout the rest of the programme, further teachings did not link to this session. Essentially meaning that students did not receive any failure training from the intervention. Why might this be the case? One reflection from the staff was that the debrief could be improved. The debrief provides an opportunity to make greater linkages with clinical work through utilising a more structured debrief pattern scenario like this for over 100 students at a time. In future iterations of the scenario clinical debrief structures (such as the 'diamond debrief': Jaye, Thomas \& Reedy, 2015) may provide students with more understanding as to the clinical relevance of the work through providing a walkthrough of failure points. It should be noted, however, that these students were $1^{\text {st }}$ year undergraduates, they will not experience regular clinical debriefs until they reach their final year rotations, some four years later. It will be interesting to observe if this cohort of students reflect on the experience differently at that point. It may be that a more realistic scenario may have generated more experiences of failure, however it would be questionable as to whether students would have engaged so much with the playful aspects of learning. As mentioned above, we did see playful behaviour in this scenario, which we consider valuable regardless (see below). Another explanation could be that as students progressed through the academic year, they in fact came to recognise the session's failure teaching and re-evaluated their own beliefs in their failure ability. Potentially their pre-intervention assessment of their ability was overinflated, and it becomes more realistic with experience. Much of this is hard to disentangle from the greater curriculum, highlighting the need for continued holistic discussion of the curriculum with students to evaluate how it develops key skills.

\section{How can play be incorporated in professional learning?}

We considered whether the inherent 'silliness' of the scenario perhaps impacted the students' ability to recognise failure. Does a highly fictionalised scenario delegitimise the learning activity? One of the most important understandings from the staff focus group was the recognition that individual students would take different learnings away from the resource. The mechanisms of play are highly personal, with individuals finding their own comfort zones. Perceptions of play as a waste of time occur even within children (Keating, Fabian, Jordan, Mavers, \& Roberts, 2000) and can be a challenge to incorporate meaningfully into work settings (Starbuck \& Webster, 1991). Playful scenarios may simply not work for all individuals, or have only limited value for some. Does it follow therefore that this form of educational exercise has lower value? One of the key elements of play is that it allows for co-creation and learner-led development (Grenier, 2010). There have been suggestions that play allows for the building of social capital, allowing learners to explore their communities in safe settings (Harris \& Daley, 2008), and for us it was imperative that we retain a highly fictionalised setting to 
allow for a safe learning environment. A more realistic scenario may well have not been so easily 'played with'. There is a question here regarding the equitability of resource in a crowded curriculum. Is it appropriate to devote a large amount of class time to a learning exercise which some students will not gain a great deal of value from? In our opinion, this is both appropriate and valuable. We make the comparison to business skills education which is incorporated into the curriculum regardless of the fact that some students already have experience in this area and may have little to gain from the instruction. We also note that students may not always be accurate judges of how useful a learning activity is, and we will be monitoring this year group to observe whether lessons are drawn from this activity in future year groups. There will be future opportunities to observe this in reflection portfolios in coming years. The session will be repeated this academic year (social distancing restrictions allowing), and is planned to repeat annually for first year students within the programme. Further evaluations will also be conducted, particularly to look at students' perceptions of their skills at various time points.

Involving students as partners in this project was a key component in its success, not simply in terms of providing extra staffing, but we also believe the student voice helped to make the scenario more authentic, and legitimised the play as being 'peer endorsed'.

\section{Considerations for future evaluations}

It is a challenge to consider effective measures for evaluating educational interventions, particularly in the short term before many of the hoped effects may be identified. However, we would encourage the post-intervention survey be delivered after the complete session, as it was not clear how much the debrief contributed to the session from the present data. This is particularly relevant with planned changes to the structure of the debrief, highlighting the description of the session, analysis of why behaviours occurred in the scenario, and application of future behaviours (diamond debrief structure). Exploring how students respond to this structure will also improve the relevance to the clinical side of the veterinary programme.

\section{Conclusions}

Playful scenarios can be utilised within professional learning contexts providing they are well-scaffolded and used sparingly. Their usage cannot be expected to be of equal learning opportunity for all students, and the challenges of giving adults permission to play can impact on their creation and utilisation. It may not be possible for all students to achieve the same 'playfulness', nor to experience 'failure' in the same way, but by demonstrating how failure is a learning process within the veterinary career, it can still be useful. Using a peersupported system may help to mitigate this. 


\section{Acknowledgements}

Author contributions:

JM designed the scenario and wrote the manuscript and provided additional analyses and interpretation.

JP conceived of the original study.

SC and KS collected the data.

KS, SC and SS contributed to data analysis.

Funding for this work was supplied via the University of Edinburgh's Principal's Teaching Award Scheme: funding title 'Vets At Play'.

\section{References}

Acharya, S., Shukla, S., Acharya, N., \& Vagha, J. (2014). Role play - an effective tool to teach clinical medicine. Journal of Contemporary Medical Education, 2(2), 1. doi:10.5455/jcme.20140619111139

Batchelor, C. E. M., Creed, A., \& McKeegan, D. E. F. (2015). A preliminary investigation into the moral reasoning abilities of UK veterinarians. The Veterinary Record, 177(5), 124. doi:10.1136/vr.102775

Batchelor, C. E. M., \& McKeegan, D. E. F. (2012). Survey of the frequency and perceived stressfulness of ethical dilemmas encountered in UK veterinary practice. Veterinary Record, 170(1), 19. doi:10.1136/vr.100262

Bergen, D. (2002). The role of pretend play in children's cognitive development. Early Childhood Research $\mathcal{E}$ Practice, 4(1), 1-13.

Bovill, C., Cook-Sather, A., \& Felten, P. (2011). Students as co-creators of teaching approaches, course design, and curricula: Implications for academic developers. International Journal for Academic Development, 16(2), 133145. doi:10.1080/1360144X.2011.568690

Bovill, C., \& Woolmer, C. (2018). How conceptualisations of curriculum in higher education influence studentstaff co-creation in and of the curriculum. Higher Education. doi:10.1007/s10734-018-0349-8

Bruni-Bossio, V., \& Willness, C. (2016). The “Kobayashi Maru” meeting. Journal of Management Education, 40(5), 619-647. doi:10.1177/1052562916644284

Bryer, J., \& Speerschneider, K. (2016). Likert: analysis and visualization Likert items. CRAN.

Cardwell, J. M., Lewis, E. G., Smith, K. C., Holt, E. R., Baillie, S., Allister, R., \& Adams, V. J. (2013). A crosssectional study of mental health in UK veterinary undergraduates. Veterinary Record, 173(11), 266-266. 
doi:10.1136/vr.101390

Chang, P.-J., Yarnal, C., \& Chick, G. (2016). The longitudinal association between playfulness and resilience in older women engaged in The Red Hat Society. Journal of Leisure Research, 2216. doi:10.18666/JLR-2016-V48-I36256

Conti, G., \& Caroland, J. (2011). Embracing the Kobayashi Maru: Why you should teach your students to cheat. IEEE Security and Privacy, 9(4), 48-51. doi:10.1109/MSP.2011.80

DeNeve, K. M., \& Heppner, M. J. (1997). Role play simulations: The assessment of an active learning technique and comparisons with traditional lectures. Innovative Higher Education, 21(3), 231-246. doi:10.1007/BF01243718

Deterding, S., Dixon, D., Khaled, R., Nacke, L., Sicart, M., \& O’Hara, K. (2011). Gamification: Using game-design elements in non-gaming contexts. CHI '11 Extended Abstracts on Human Factors in Computing Systems (CHI EA '11), 2425-2428. doi:10.1145/1979742.1979575

Eukel, H. N., Frenzel, J. E., \& Cernusca, D. (2017). Educational gaming for pharmacy students - Design and evaluation of a diabetes-themed escape room. American Journal of Pharmaceutical Education, 81(7). doi:10.5688/ajpe8176265

Feldman, C. F. (2005). Mimesis: Where play and narrative meet. Cognitive Development, 20(4), 503-513. doi:10.1016/j.cogdev.2005.08.006

Frost, J. L. (2004). How adults enhance or mess up children's play. Archives of Pediatrics $\mathcal{E}$ Adolescent Medicine, 158(1), 16. doi:10.1001/archpedi.158.1.16

Gee, J. P. (2003). What video games have to teach us about learning and literacy. Computers in Entertainment, 1(1), 20. doi:10.1145/950566.950595

Gordon, G. (2009). What is play? In search of a universal definition. In D.S. Kuschner (Ed.), From children to Red Hatters: Diverse images and issues of play (pp. 1-13). Plymouth: University Press of America. Retrieved from http://www.gwengordonplay.com/pdf/what_is_play.pdf

Grenier, R. S. (2010). All work and no play makes for a dull museum visitor. New Directions for Adult and Continuing Education, (127), 77-85. doi: 10.1002/ace.383

Harris, P., \& Daley, J. (2008). Exploring the contribution of play to social capital in institutional adult learning settings. Australian Journal of Adult Learning, 48(1), 50-70.

Hudson, N., Stansbie, N., Rhind, S., Brown, G., Handel, I., Mellanby, R., \& Bell, C. (2016). Recognising and developing students as teachers: Introduction of a novel Undergraduate Certificate in Veterinary Medical 
Education. Medical Teacher, 38(2), 208-210. doi:10.3109/0142159X.2015.1078891

Jaye, P., Thomas, L., \& Reedy, G. (2015). 'The Diamond': a structure for simulation debrief. The Clinical Teacher, 12(3), 171-175. doi:10.1111/tct.12300

Joyner, B., \& Young, L. (2006). Teaching medical students using role play: twelve tips for successful role plays. Medical Teacher, 28(3), 225-229. doi:10.1080/01421590600711252

Keating, I., Fabian, H., Jordan, P., Mavers, D., \& Roberts, J. (2000). “Well, I've not done any work today. I don't know why I came to school". Perceptions of play in the reception class. Educational Studies, 26(4), 437-454. doi:10.1080/0305569002000363

Langebæk, R., Eika, B., Tanggaard, L., Lundorff, A. L., \& Berendt, M. (2012). Emotions in veterinary surgical students: A qualitative study. Journal of Veterinary Medical Education, 39(4), 312-321. doi:10.3138/jvme.0611.068R1 Magalhaes-Sant'Ana, M. (2014). Ethics teaching in European veterinary schools: A qualitative case study. Veterinary Record, 175(23), 592-592. doi:10.1136/vr.102553

Main, D. C. J., Thornton, P., \& Kerr, K. (2005). Teaching animal welfare science, ethics, and law to veterinary students in the United Kingdom. Journal of Veterinary Medical Education, 32(4), 505-508. Retrieved from http://www.ncbi.nlm.nih.gov/pubmed/16421835

Morse, S., Littleton, F., Macleod, H., \& Ewins, R. (2009). The theatre of performance appraisal: Potential for roleplay training in Second Life. In C. Wankel \& J. Kingsley (Eds.), Higher education in virtual worlds: Teaching and learning in Second Life (pp. 181-202). Bingley: Emerald.

Mullan, S. M. (2012). Ethical decision-making in veterinary practice: using the head and the heart. Veterinary Record, (171), 443-444. doi:10.1136/vr.e7344

RCVS. (2014). Day one competences. Retrieved from https://www.rcvs.org.uk/document-library/day-onecompetences/

RCVS. (2019). Code of professional conduct for veterinary surgeons. Retrieved from https://www.rcvs.org.uk/settingstandards/advice-and-guidance/code-of-professional-conduct-for-veterinary-surgeons/

Rhind, S. M., \& Grant, A. (2017). From studying the rain to studying the umbrella: Mental health and well-being of veterinary medical students and graduates. Journal of Veterinary Medical Education, 44(1), 1-2.

doi:10.3138/jvme.1116-170

Rhind, S. M., \& Paterson, J. (2015). Assessment literacy: Definition, implementation, and implications. Journal of Veterinary Medical Education, 42(1), 28-35. doi:10.3138/jvme.0714-067R1 
Snyder, B. R. (1971). The hidden curriculum. New York, NY: MIT Press.

Starbuck, W. H., \& Webster, J. (1991). When is play productive? Accounting, Management and Information Technologies, 1(1), 71-90. doi:10.1016/0959-8022(91)90013-5

Statler, M., Heracleous, L., \& Jacobs, C. D. (2011). Serious play as a practice of paradox. Journal of Applied Behavioral Science, 47(2), 236-256. doi:10.1177/0021886311398453

Stemwedel, J. D. (2015, August 23). The philosophy of Star Trek: The Kobayashi Maru, no-win scenarios, and ethical leadership. Forbes. Retrieved from https://www.forbes.com/sites/janetstemwedel/2015/08/23/thephilosophy-of-star-trek-the-kobayashi-maru-no-win-scenarios-and-ethical-leadership/\#6b8b46055f48

Walsh, A. (2019). Giving permission for adults to play. The Journal of Play in Adulthood, 1(1), 1-14. doi:10.5920/jpa.565

West, S., Hoff, E., \& Carlsson, I. (2016). Play and productivity: Enhancing the creative climate at workplace meetings with play cues. American Journal of Play, 9(1), 71-87.

Whittington, R. E., Rhind, S. M., Loads, D., \& Handel, I. (2017). Exploring the link between mindset and psychological well-being in veterinary students. Journal of Veterinary Medical Education, 44(1), 134-140.

Whitton, N. (2015). Beyond gamification: Play in higher education. Creative Academic Magazine, June(2), 22-23. Retrieved from http://www.creativeacademic.uk/uploads/1/3/5/4/13542890/cam_2b.pdf\#page=22

Whitton, N., \& Maclure, M. (2015). Video game discourses and implications for game-based education. Discourse: Studies in the Cultural Politics of Education, 6306(December), 1-12. doi:10.1080/01596306.2015.1123222 Yeager, D. S., \& Dweck, C. S. (2012). Mindsets that promote resilience: When students believe that personal characteristics can be developed. Educational Psychologist, 47(4), 302-314. doi:10.1080/00461520.2012.722805 